\title{
Heterologous neutralization breadth persists despite B-lymphocyte dysfunction in chronic HIV-1 infection
}

\author{
MK Murphy", S Boliar, TC Tran, DG Carnathan, WS Armstrong, G Silvestri, CA Derdeyn \\ From AIDS Vaccine 2012 \\ Boston, MA, USA. 9-12 September 2012
}

\section{Background}

Of the millions globally infected with HIV-1, only $20-30 \%$ will develop broadly neutralizing antibodies. To date, no one has measured this phenomenon in a cohort of subjects for which multiple aspects of B-lymphocyte dysfunction have been evaluated in parallel.

\section{Methods}

In 16 viremic seroconverters, the cross-clade neutralizing activity of plasma was investigated using a panel of thirteen clade A, B, and C HIV-1 envelope (Env) pseudotyped virions, which represented three tiers of sensitivity. The neutralization IC50 was calculated for each plasma-Env combination, and these data were used to determine a breadth (how many Envs were neutralized) and potency (the strength of neutralization) score for each seroconverter. Additionally, the level of plasma antibodies that bound to the monomeric form of a subtype B Env gp120 (HIV-1 $\mathrm{BaL})$ was quantitated.

\section{Results}

A range of neutralization breadth emerged: three plasma samples (19\%) demonstrated widespread neutralizing activity against this panel of Envs, while five subjects (31\%) exhibited a complete lack of detectable neutralization at the lowest dilution of plasma tested (1:100). No correlation was observed between neutralization breadth or potency and parameters of B-lymphocyte dysfunction (PD-1, BTLA), immune activation (Ki-67, CD95), or disease progression (CD4 T cell count, plasma viral load). The level of total IgG in each plasma sample, however, did significantly correlate with both neutralization breadth and potency. Like total IgG, anti-gp120 binding antibodies also positively correlated, but, in this case, the correlations only trended toward significance. Anti-gp120 binding antibodies did not correlate with parameters of B-lymphocyte dysfunction, immune activation, disease progression, or total IgG level.

\section{Conclusion}

These findings demonstrate that even in chronically HIV1-infected subjects in whom B-lymphocytes display multiple indications of dysfunction, antibodies that mediate cross-clade neutralization breadth (particularly anti-gp120 binding and other IgG antibody specificities) continue to circulate in plasma.

Published: 13 September 2012

doi:10.1186/1742-4690-9-S2-P103

Cite this article as: Murphy et al:: Heterologous neutralization breadth persists despite B-lymphocyte dysfunction in chronic HIV-1 infection. Retrovirology 2012 9(Suppl 2):P103.

Submit your next manuscript to BioMed Central and take full advantage of:

- Convenient online submission

- Thorough peer review

- No space constraints or color figure charges

- Immediate publication on acceptance

- Inclusion in PubMed, CAS, Scopus and Google Scholar

- Research which is freely available for redistribution 